In this forum we highlight innovative thought, design, and research in the area of interaction design and sustainability, illustrating the diversity of approaches across $\mathrm{HCl}$ communities. - Roy Bendor, Editor

\title{
Championing Environmental and Social Justice
}

\author{
Embracing, Embedding, and Promoting \\ Broader Notions of Sustainability in $\mathrm{HCl}$
}

Oliver Bates, Lancaster University, Vanessa Thomas, Lickable Cities, Christian Remy, Aarhus University,

Adrian Friday, Lancaster University, Lisa Nathan, University of British Columbia,

Mike Hazas, Lancaster University, Samuel Mann, Otago Polytechnic

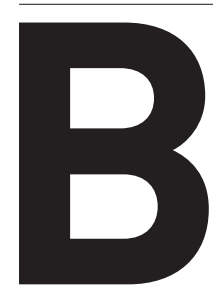

ig question: What will it take for sustainable HCI to really make a difference? As this forum's editor has pointed out, continuous dialogue is key [1]. It is clear that the digital systems designed by the HCI community have increasingly powerful and complex effects on the more-than-human world and on humans who adopt our systems [2]. Many HCI researchers, including the authors of this article, believe that we should interrogate the use of technology for good [3,4], especially when confronting urgent social and environmental challenges.

Countless reports, articles, and documentaries tell versions of the same crushing story: how globally intertwined and digitally mediated economies exploit people. It is too easy to become numb to endless reports of human suffering and ecosystem collapse. Entrenched inequities and discrimination, as well as a shrugging acceptance of business-as-usual, propels us along. In an effort to disrupt this, we, the authors, organized a Sustainable HCI (SHCI) Special Interest Group (SIG) at CHI 2018, aiming to bring together people who share an interest in these complex and interconnected issues [5]. To provide a more comprehensive framing for the sustainable HCI community, we proposed championing environmental and social justice together. The intertwined set of issues relating to society (e.g., inequality, justice, diversity, privilege) and the environment are often seen as separate in HCI. Through this SIG we began to take stock of the multitude of these issues, broadening our worldview and taking more responsibility as technologists whose work affects society and the environment.

The SIG attracted just over 40 engaged researchers and practitioners - as well as one telepresence robot-with diverse areas of expertise. Many of the attendees were relatively new to the work produced by SHCI and socialjustice-focused HCI researchers. What attracted attendees to the SIG was a shared eagerness to discuss how to pursue, promote, and continue strengthening research related to interaction design and issues of environmental and social justice. In this article, we provide an overview of our discussions and where we see room for continued dialogue.

\section{DEEPLY EMBEDDING RESPONSIBILITY IN HCI}

Many attendees expressed an interest in seeing concerns about social and

\footnotetext{
Insights

$\rightarrow$ Digital technology is mediating

socioeconomic, sociopolitical,

and sociotechnical systems

that entrench inequality

and unsustainability.

$\rightarrow$ Sustainable $\mathrm{HCl}$ can find

new energy and become

more diverse by engaging

under a broader banner

such as environmental

and social justice.
}

environmental justice become more deeply embedded in HCI research, practice, and community events (e.g., conferences and workshops) to demonstrate that HCI is taking these issues seriously. This led to several discussions about the shared vision or values among what we might see as the community. Who are the members of this community? Should they interact in ways beyond purely conducting research, writing it up, and providing constructive peer review to one another? Should the community attempt to incorporate its interests into postgraduate and undergraduate teaching? How might we encourage researchers from other domains within $\mathrm{HCI}$ and beyond to become involved with social and environmental issues?

We acknowledged the difficulty of answering these questions definitively, particularly due to the diverse nature of global and local issues related to environmental and social justice. As several attendees pointed out, researchers new to these issues in $\mathrm{HCI}$ can struggle to get an overview of what has been done before and where they might best use their skills and knowledge. With the wide-ranging body of relevant research growing every year, even survey papers might be an insufficient source of information for newcomers. An open challenge is how to appropriately bring new HCI researchers into this domain and make them part of the ongoing discussion.

An alternative way to incorporate newcomers might be through making environmental sustainability and 
social justice more core issues at the $\mathrm{CHI}$ conference itself. Building on a recent proposal by ACM's Future of Computing Academy that suggested that researchers could consider broader project impacts [6], we wondered: Should every CHI paper contain a paragraph commenting on how the outcomes of the research might affect environmental and social justice? If so, how can we engage with the difficult challenge of evaluating these impacts? Additionally, we wondered if a frank but constructive criticism of companies producing digital devices and online services might be built into the student design competition in some way. And where are sustainability and social justice at the plenary/keynote level? It is hard to imagine more pressing issues confronting the HCI community!

\section{WALKING THE WALK}

Several participants expressed a concern that if a community of environmental- and socialjustice-oriented HCI researchers and practitioners were to become formalized, it should do more to expand its diversity and inclusion efforts. This raised many questions about how to more deeply integrate justice into the roots of our community. For example, how can we make research and policy development related to environmental and social justice more visible across HCI? Do we require more top-down approaches advocating sustainability as "responsible innovation" and "social responsibility" within SIGCHI and ACM? Attendees proposed and discussed the potential for a group of environmental or social justice ambassadors to help address these systemic issues.

Environmental or social ambassadors might be able to support knowledge sharing and agenda setting within SIGCHI and ACM, thereby promoting sustainability and supporting the growth of a diverse community. Some responsibilities for the ambassadors might include broadening the range of inclusive social events during conferences, highlighting the unsustainability of food waste at conferences, building stronger bonds with like-minded

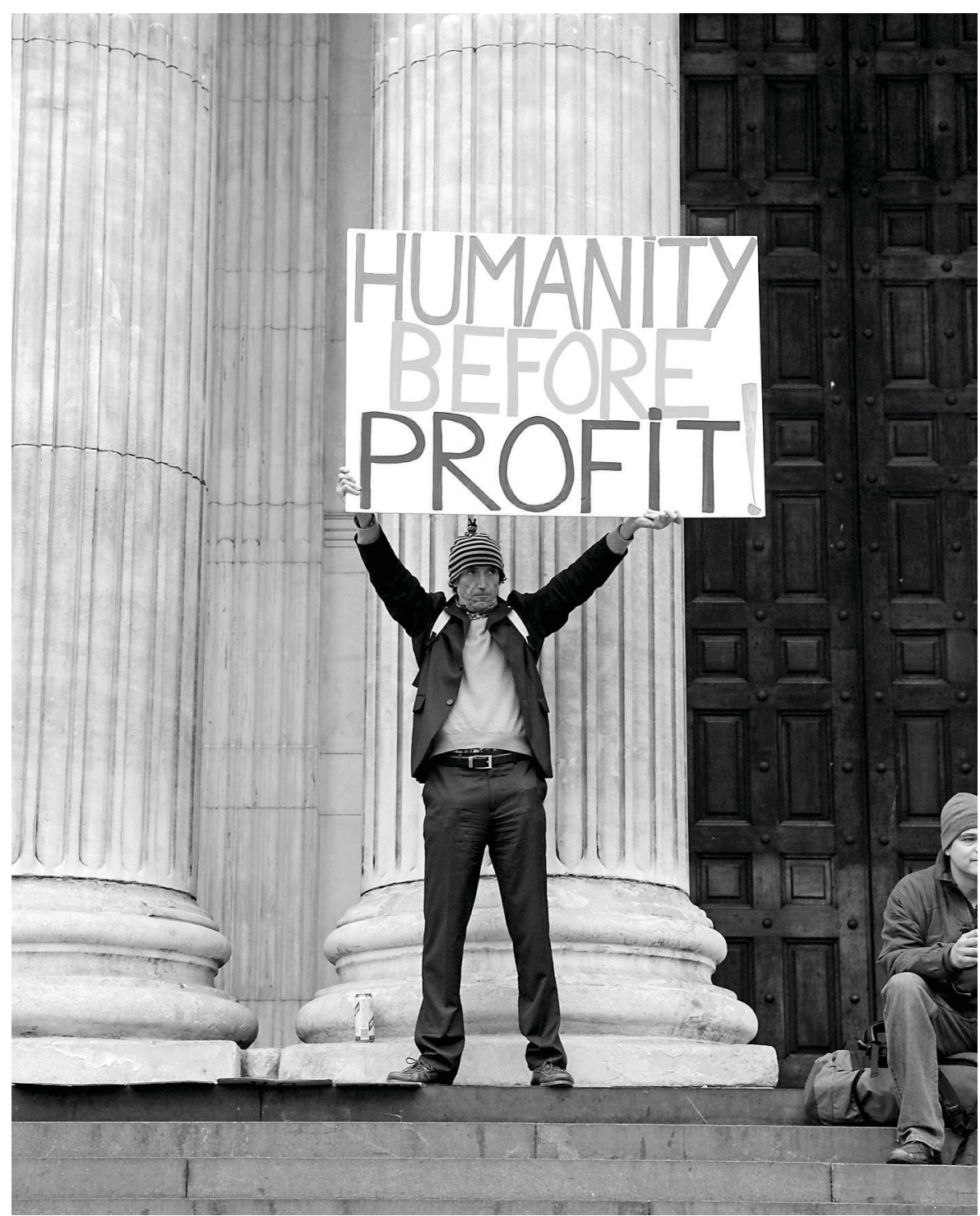

communities (e.g., HCI4D, feminist $\mathrm{HCI}$, civic design, third sector $\mathrm{HCI}$ ), and speaking directly to future conference organizers about centering environmental and social justice issues during keynotes to set a meaningful precedent. These ambassadors may also help the community-at-large advocate for installing a sustainability adjunct chair on various conference steering committees.

\section{Should every $\mathrm{CHI}$ paper contain a paragraph on how the outcomes of the research might affect environmental and social justice?}

\section{THE PRIVILEGE TO PURSUE ACTIVIST RESEARCH}

Numerous SIG attendees expressed a concern about the real and perceived risks of pursuing the kind of longterm research projects needed to address environmental and social justice issues. Not all researchers are currently privileged enough to pursue this sort of research, either due to their career stage or precarious work arrangement (e.g., shortterm contracts, restrictive funding structures, potential visa issues). On the other hand, short-term projects also carry risks, particularly when relationships and trust are critical for success. Many attendees agreed that a supportive research community with engaged senior academics and the aforementioned community ambassadors-especially if those 


\section{DFORUM SUSTAINABILITY IN (INTER)ACTION}

HARNIESSING

THIㅡㄹ

COMMUNITY'S

ENIERGY

There is a sizable community of

interaction designers working on and

interested in environmental and social

justice. We are emboldened by our

latest SHCI SIG, and we now hope to

energize a wider community interested

in championing environmental and social

justice. We invite readers to join our

longstanding SHCI mailing list (https://

groups.google.com/forum/\#!forum/

sustainable-chil and catalyze or

get involved with conversations and

activities. We also want readers to

know that since the SIG, we've started

a Twitter account (http://twitter.com/

sustainable_hci hashtag: \#SHCI) and

created a Slack channel so people can

meet and share information about social

and environmental justice /http://hci-

sustainability.slack.com-email Oliver

Bates, info in bio, for an invite). We have

also been in direct contact with CHI 2019

conference chairs to discuss embedding

environmental and social justice in the

core of next year's conference. Lastly,

we've started developing a case with help

from program committee members to

put in a proposal that demands an adjunct

chair of environmental and social justice

for CHI 2020.

ambassadors were to be involved with ACM - might help address these issues.

\section{ENGAGEMENT BEYOND THE CHI CONFERENCE}

SIGs offer an opportunity to meet like-minded researchers and discuss future collaborations. Many of our SIG's attendees shared a general feeling that they were amidst a passionate group, and that they were perhaps missing out on opportunities to support one another due to rather loose affiliation and organization, both within the CHI context and beyond. We wondered about possible improvements: At a very basic level, some community resources or some sort of digital space in which to spark discussions about potential collaborative projects and grant applications, identify our gaps, share our research, and establish our identities - beyond the existing mailing lists and static resources-could help. This could broker access to established experts whom one might consult (e.g., related to eco-feedback, transport, food, charities, life cycle assessment) and provide a list of alternative venues for publication (e.g., ACM Computing within Limits (LIMITS), ICT for Sustainability (ICT4S), and ACM Computing and Sustainable Societies (CompaSs), which are wonderful events for meeting new people and trying out new ideas).

\section{REFLECTING \\ ON NEXT STEPS}

There are so many exciting opportunities to pursue and next steps that we could take if we want to more directly orient HCI toward environmental and social justice. If our SIG demonstrated anything, it was that a broad group of HCI researchers has the energy for and an interest in tackling the interwoven issues of social and environmental justice. To support this energy and promote broader notions of sustainability, we call on the SHCI community to support a more holistic approach in which a set of shared values and ethics is recognized as central to SHCI's vision. We believe that forging the community in such a way is essential for more directly orienting HCI toward environmental and social justice.

We were thrilled to hear our SIG attendees calling for more visibility of existing environmental and social justice research and projects, SIGCHI to improve its representation of these issues, and increased action and activism that can support the energy and enthusiasm of attendees. We agreed with and intend to support action toward achieving these goals. What we also heard from attendees was that there is a significant number of HCI researchers interested in social and environmental justice. In the coming years, we intend to encourage, establish, and support a number of champions within HCI and SIGCHI who can push for environmental and social justice at different levels in our organizations

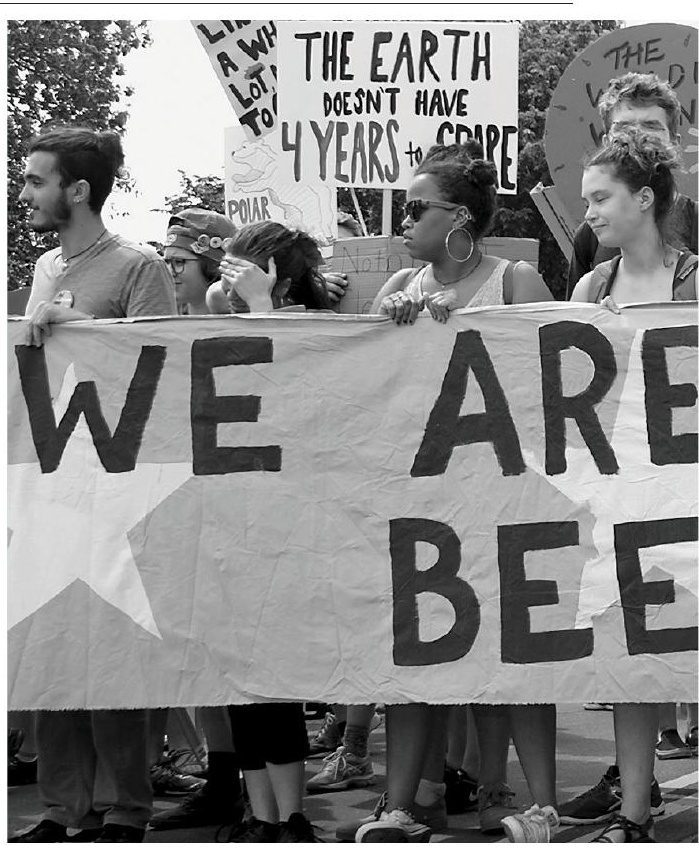

and communities, from different directions and at different paces.

While there is value in transforming SIGCHI and ACM at the top to help establish the institutional legitimacy of our concerns and influence the direction of interaction design, we believe the SHCI community could focus its efforts on other avenues. We could expand the reach and power of our community if we actively talk about environmental and social justice in our research, Twitter feeds, and conversationswith policymakers, our peers, and members of the public.

To help HCI evolve so that it can engage these challenges and transform sustainability issues relating to climate change, environment, and resource consumption, we must more deeply consider issues where technology, energy, and the environment are implicated in issues of injustice, inequity, and discrimination.

How can we be more active in this space? We can choose to include a few paragraphs in our CHI papers 


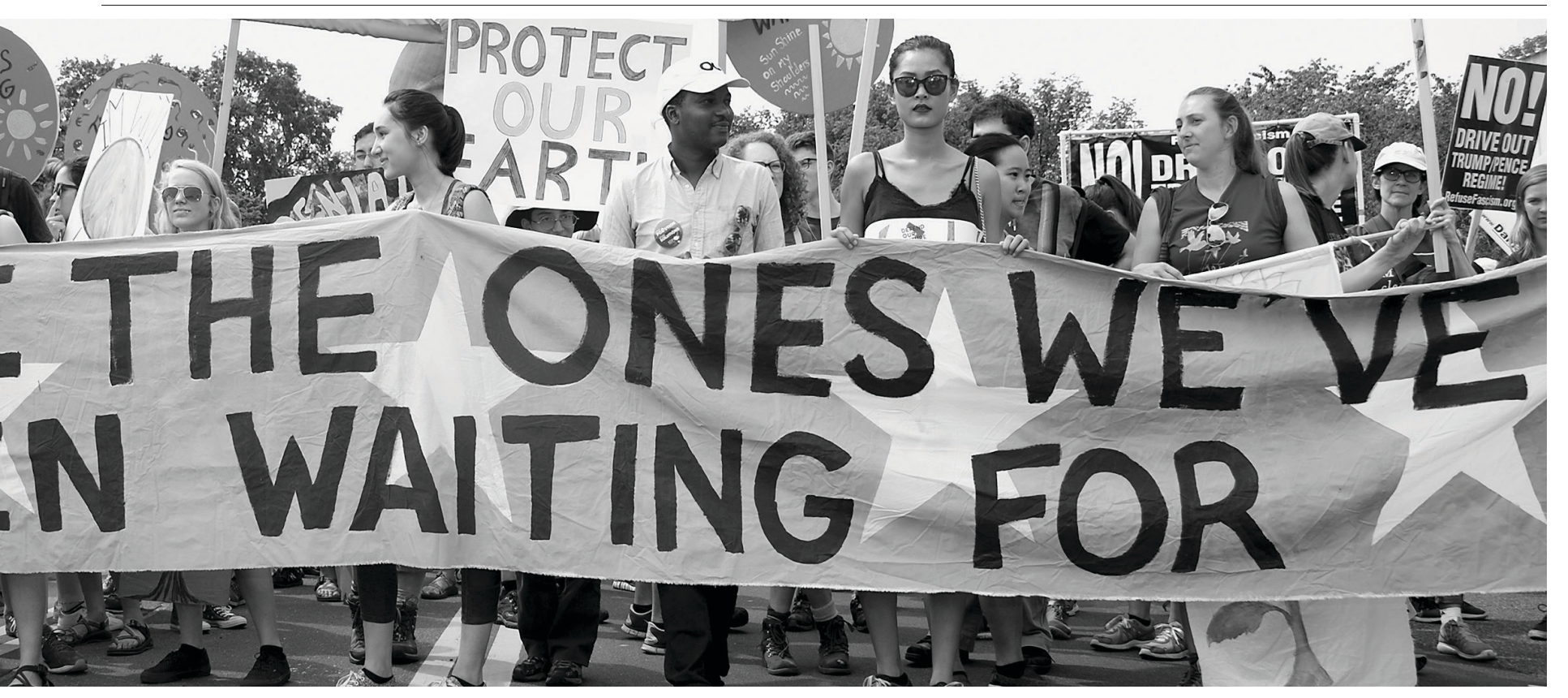

commenting on how our research might affect environmental and social issues, and we can bring these issues up when presenting our work in public. We can have a conversation with our students and advisees, or bring up these issues during project meetings and workshops. The opportunities to more directly orient HCI toward environmental and social justice are varied, and we believe they shouldn't be restricted to SIGCHI or any single ACM-sponsored conference. Environmental and social justice can and should be ingrained in every interaction design project. There is no single right way to make progress on the diverse issues related to environmental and social justice. All of our interactions matter.

\section{ENDNOTES}

1. Bendor, R. Sustainability, hope, and designerly action in the Anthropocene. Interactions 25, 3 (2018), 82-84.

2. Eubanks, V. Automating Inequality: How High-Tech Tools Profile, Police, and Punish the Poor. St. Martin's Press, 2018.

3. Bates, O., Thomas, V. and Remy, C. Doing good in HCI: Can we broaden our agenda? Interactions 24, 5 (2017), 80-82.

4. Pal, J. The fallacy of good: Marginalized populations as design motivation. Interactions 24, 5 (2017), 65-67; https:// doi.org/10.1145/3121393

5. Bates, O., Thomas, V., Remy, C., Nathan, L., Mann, S., and Friday, A. The future of HCI and sustainability:
Championing environmental and social justice. Extended Abstracts of the 2018 CHI Conference on Human Factors in Computing Systems. ACM, New York, 2018, Paper SIG01; https://doi. org $/ 10.1145 / 3170427.3185365$

6. Hecht, B., Wilcox, L., Bigham, J.P., Schöning, J., Hoque, E., Ernst, J., Bisk, Y., De Russis, L., Yarosh, L., Anjum, B., Contractor, D., and Wu, C. It's time to do something: Mitigating the negative impacts of computing through a change to the peer review process. ACM Future of Computing Blog. Mar. 29, 2018; https://acm-fca.org/2018/03/29/ negativeimpacts/

\section{(1) Oliver Bates is a senior research}

associate in the School of Computing and Communications at Lancaster University, U.K., and is the acting head of the SIGCHI HCl and Sustainability community. His passion is developing research and teaching under the banner of responsible and sustainable computing, promoting environmental and social justice.

$\rightarrow$ o.batesQlancaster.ac.uk

(1) Vanessa Thomas recently left the academic precariat to pursue a full-time, permanent, unionized civic service position: EPCOR Water Service's technical and online learning advisor. In her spare time, she continues to co-run the Lickable Cities project and research how digital technologies are entwined with social and environmental justice.

$\rightarrow$ vanessa.thomasagmail.com

(1) Christian Remy is an assistant professor in the Centre for Digital Creativity at Aarhus University in Denmark. His research interests span sustainable $\mathrm{HCl}$, sustainable interaction design, ubiquitous computing, design patterns, $\mathrm{HCl} 4 \mathrm{D}$, issues of evaluation, design and creativity, and interactive technologies. $\rightarrow$ remyacc.au.dk

(4) Adrian Friday is a professor of

sustainability and computing in the School of Computing and Communications at Lancaster University. His current work focuses on a range of sustainability topics, including more sustainable parcel deliveries, developing a campus energy information system, and promoting adaptive thermal comfort in nondomestic buildings.

$\rightarrow$ a.fridayalancaster.ac.uk

(4) Lisa Nathan is associate professor and First Nations Coordinator at the University of British Columbia's iSchool. She is thrilled to pass the baton of Interactions' Sustainability in (Inter)Action forum to Roy Bendor.

$\rightarrow$ lisa.nathanaubc.ca

(4) Mike Hazas is a reader in the School of Computing and Communications at Lancaster University. He interrogates how digital systems such as learning thermostats, smartphones, superfast broadband, and robotic vacuum cleaners contribute to increasing standards for comfort and service provision, and thus tend to ratchet energy demand and carbon emissions.

$\rightarrow$ m.hazasalancaster.ac.uk

(4) Samuel Mann is a professor of sustainable practice at Capable NZ, Otago Polytechnic,

New Zealand. He is currently pioneering a new degree scheme in professional practice at Capable NZ. He is passionate about ingraining the transformation mindset in computing to promote hope and sustainability in research and teaching.

$\rightarrow$ samuel.manndop.ac.nz 